\title{
Modeling Time-Varying Currency Betas: New Evidence from the Selected Markets
}

\author{
P. Jayasinghe ${ }^{\mathrm{a}}$, A.K. Tsui ${ }^{\mathrm{b}}$ and $\underline{\text { Z.Y. Zhang }}$ \\ ${ }^{a}$ Department of Business Economics, University of Colombo, Sri Lanka \\ ${ }^{b}$ Department of Economics, National University of Singapore, Singapore \\ ${ }^{c}$ School of Accounting, Finance \& Economics, Edith Cowan University, Australia \\ Email: zhaoyong.zhang@ecu.edu.au
}

\begin{abstract}
In the past decade, studies of exchange rate exposure have mainly focused on three approaches. The first approach uses conventional methods such as sub-sampling, dummy variables, and overlapping moving window regression to capture exchange rate exposure. The second approach uses pre-specified determinants of exposure coefficients to analyze the time-variation of exchange rate exposure. For example, Allayannis (1997) suggests that currency beta is determined by export and import shares, and finds support for time-variation of exposure in some 4-digit level SIC industries. The third approach employs time-varying second moments to derive time-varying exchange rate exposure (see, for instance, Hunter, 2005; Lim, 2005). Hunter (2005) analyzes the time-varying exchange rate exposure of small and large firms using size-based portfolios of the Fama-French-type, and Lim (2005) derives both market and currency betas at country level, with allowance for non-orthogonality between risk factors.

It is believed that the third approach is more appealing as the well-documented bivariate GARCH-type models are often employed to estimate the time-varying exchange rates conditional on available information. There are three models associated with this approach, namely, the VECH models; the BEKK models; and the Constant Conditional Correlation GARCH (CCC-GARCH) models. However, the VECH model is less popular because of the difficulty in maintaining positive definiteness of the variance and covariance matrix and other computational hindrance on convergence during estimation, while the CCC-GARCH model is too restrictive as the computed covariance between returns and exchange rate changes can be either negative or positive in all periods, depending on the sign of the constant conditional correlation coefficient. In reality, exchange rate changes may affect returns on stock index either positively and/or negatively in different time periods. Hence, it is inappropriate to assume time-constancy in the conditional correlation coefficient.

In this paper, we adopt the general framework of conditional ICAPM proposed by Adler and Dumas (1983) and De Santis and Gerard (1998) to estimate the time varying currency betas and the time-varying market betas for nine developed and emerging countries. A trivariate BEKK-GARCH-type model is used to estimate the conditional variance and covariance of return variables using a set of daily data spanning from 5 January 1999 to 30 December 2005. In particular, we compute the time-varying currency betas and market betas using estimates of the conditional variance and covariance of returns from country stock index, world market portfolio and changes in exchange rate of the trading country. To the best of our knowledge, this is the first study that estimates such betas from a BEKK-GARCH-type specification based on daily returns. The main advantage of BEKK parameterization is that it guarantees the variance and covariance matrix to be positive definiteness during estimation, and the often alleged difficulty of interpreting parameters in BEKK models is not an issue. Our results indicate that currency betas are generally more volatile than that of the world market betas. In addition, currency betas in the emerging markets, such as Korea, Taiwan and Thailand, are more volatile than those in the developed markets. We also find some evidence of long-memory in the estimated currency betas. The findings have important implications for investment and hedging strategies.
\end{abstract}

Keywords: Time-varying currency betas; multivariate GARCH-M models; international CAPM; fractionally integrated processes; stochastic dominance 


\section{INTRODUCTION}

In the recent decade, studies of exchange rate exposure have mainly focused on three approaches. The first approach uses conventional methods such as sub-sampling, dummy variables, and overlapping moving window regression to capture exchange rate exposure (See, among others, Williamson, 2001; Bodner and Wong, 2003; and Dominguez and Tesar, 2006). The second approach uses pre-specified determinants of exposure coefficients to analyze the time-variation of exchange rate exposure. For example, Allayannis (1997) suggests that currency beta is determined by export and import shares, and finds support for timevariation of exposure in some 4-digit level SIC industries. Similar approaches are used by Chiao and Hung (2000), Allayannis and Ihrig (2001), and Bodner et al. (2002). The third approach employs time-varying second moments to derive time-varying exchange rate exposure (see, for instance, Hunter, 2005; Lim, 2005). Hunter (2005) analyzes the time-varying exchange rate exposure of small and large firms using size-based portfolios of the Fama-French-type, and Lim (2005) derives both market and currency betas at country level, with allowance for non-orthogonality between risk factors.

There are three models associated with the third approach, namely, the VECH models (see for instance Choudhry, 2001 and 2002; Giannopoulos, 1995; and McClain et al., 1996); the BEKK models (see Choudhry, 2005; Gonzalez-Rivera, 1996); and the Constant Conditional Correlation GARCH (CCCGARCH) models (see Brooks et al., 2000 and 2002). However, the VECH model is less popular because of the difficulty in maintaining positive definiteness of the variance and covariance matrix and other computational hindrance on convergence during estimation, while the CCC-GARCH model is too restrictive as the computed covariance between returns and exchange rate changes can be either negative or positive in all periods, depending on the sign of the constant conditional correlation coefficient. In reality, exchange rate changes may affect returns on stock index either positively and/or negatively in different time periods. Hence, it is inappropriate to assume time-constancy in the conditional correlation coefficient.

In this paper, we adopt the general framework of conditional ICAPM proposed by Adler and Dumas (1983) and De Santis and Gerard (1998) to estimate the time varying currency betas and the time-varying market betas for nine developed and emerging countries. A trivariate BEKK-GARCH-type model is used to estimate the conditional variance and covariance of return variables using a set of daily data spanning from 5 January 1999 to 30 December 2005. In particular, we compute the time-varying currency betas and market betas using estimates of the conditional variance and covariance of returns from country stock index, world market portfolio and changes in exchange rate of the trading country. To the best of our knowledge, this is the first study that estimates such betas from a BEKK-GARCH-type specification based on daily returns. The main advantage of BEKK parameterization is that it guarantees the variance and covariance matrix to be positive definiteness during estimation, and the often alleged difficulty of interpreting parameters in BEKK models is not an issue. Our results indicate that currency betas are generally more volatile than that of the world market betas. In addition, currency betas in the emerging markets, such as Korea, Taiwan and Thailand, are more volatile than those in the developed markets. We also find some evidence of long-memory in the estimated currency betas. The findings have important implications for investment and hedging strategies.

The rest of this paper is organized as follows. In Section 2, we discuss the methodology employed in this study and the BEKK-GARCH-in mean-type models to estimate currency betas and market betas from the conditional variance and covariance of return variables. Section 3 presents the sample data and discuss the main empirical findings. Some concluding remarks are given in Section 4.

\section{METHODOLOGY AND THE MODEL}

The international asset pricing model (ICAPM) is an extension of the standard CAPM by Adler and Dumas (1983), in which a representative investor is concerned about variance of the return on the world market portfolio and about the covariance of the invested asset return with each of the exchange rates of various countries. In a world of $(L+1)$ countries, the expected excess returns on equity/asset $i$ can be expressed as:

$$
E_{t-1}\left(r_{i, t}\right)=\lambda_{m, t-1} \operatorname{Cov}_{t-1}\left(r_{i, t}, r_{m, t}\right)+\sum_{l=1}^{L} \lambda_{\pi, l, t-1} \operatorname{Cov}_{t-1}\left(r_{i, t}, \pi_{l, t}\right)
$$

where $E_{t-1}($.$) and \operatorname{Cov}_{t-1}($.$) denote the expectation and covariance, conditional on the available information$ set $I_{t-1}$ at time $(t-1) . \quad r_{i, t}$ denotes the excess return on asset $i$ denominated in any numeraire currency; $r_{m, t}$ denotes the excess return on the world market portfolio denominated in the base currency; $\pi_{l, t}$ denotes the 
Jayasinghe et al., Modeling Time-Varying Currency Betas

inflation rate in country $l$ which includes the domestic inflation and changes in exchange rate; $\lambda_{m, t-1}$ is the price of world market risk. The covariance between $r_{i, t}$ and $r_{m, t}$ measures the world market risk. In addition, $\lambda_{\pi, l, t-1}$ denotes the price of asset risk in country $l$ and the covariance between $r_{i, t}$ and $\pi_{l, t}$ is used to gauge the inflation risk and the risk of exchange rate changes. We allow for possible non-orthogonality relationship between the world market returns and exchange rate changes, which leads to the specifications for the expected returns for stock index, world market portfolio and changes in exchange rate

To investigate the properties of time-varying currency betas, we can rewrite the conditional ICAPM relationship in (1) as the sum of the product of time varying betas and the respective expected returns of risk factors,

$$
E_{t-1}\left(r_{i, t}\right)=\beta_{m, t-1} E_{t-1}\left(r_{m, t}\right)+\beta_{x, t-1} E_{t-1}\left(r_{x, t}\right) .
$$

where $\beta_{m, t-1}=\frac{\operatorname{Cov}_{t-1}\left(r_{i, t}, r_{m, t}\right)}{\operatorname{Var}_{t-1}\left(r_{m, t}\right)}$ and $\beta_{x, t-1}=\frac{\operatorname{Cov}_{t-1}\left(r_{i, t}, r_{x, t}\right)}{\operatorname{Var}_{t-1}\left(r_{x, t}\right)}$. The world market beta $\left(\beta_{m, t-1}\right)$ measures the asset's exposure to the world market risk while the currency beta $\left(\beta_{x, t-1}\right)$ measures its exposure to the currency risk.

We employ a trivariate $\operatorname{BEKK}(k)-\operatorname{GARCH}(p, q)$-M (in mean) model to estimate the currency betas and market betas from the conditional second moments of various returns. The mode is specified as follows:

$$
\begin{aligned}
& r_{j, t}=\lambda_{0, j}+\lambda_{X} h_{X, t}+\lambda_{M} h_{M, t}+\theta_{j} \varepsilon_{j, t-1}+\varepsilon_{j, t} \quad j=i, m, x \\
& \varepsilon_{t}=z_{t} H_{t}^{1 / 2} \\
& \varepsilon_{t}\left|I_{t-1}=\left(\varepsilon_{i, t} \varepsilon_{m, t} \varepsilon_{x, t}\right)^{\prime}\right| I_{t-1} \sim N\left(0, H_{t}\right) \\
& H_{t}=C^{\prime} C+\sum_{k=1}^{K} \sum_{l=1}^{q} A_{k l}^{\prime} \varepsilon_{t-1} \varepsilon_{t-1}^{\prime} A_{k l}+\sum_{k=1}^{K} \sum_{n=1}^{p} B_{k n}^{\prime} H_{t-1} B_{k n} \\
& H_{t}=\left[\begin{array}{ll}
H_{t}^{q q} & H_{t}^{q k} \\
H_{t}^{k q} & H_{t}^{k k}
\end{array}\right] \\
& {\left[\begin{array}{l}
\beta_{x, t-1} \\
\beta_{m, t-1}
\end{array}\right]=\left[\begin{array}{ll}
H^{k k}
\end{array}\right]^{-1} H^{k q}}
\end{aligned}
$$

Where $r_{j, t}$ is the $3 \times 1$ vector consisting of returns from time $(t-1)$ to time $t$ on country index $\left(r_{i, t}\right)$, return on the world market portfolio $\left(r_{m, t}\right)$ and changes in bilateral nominal exchange rate between the US dollar and currency of the trading country $i\left(r_{x, t}\right)$, respectively. Parameters $\lambda_{M}$ and $\lambda_{X}$ denote constant market price of risk and currency price of risk, and $h_{X, t}$ and $h_{M, t}$ are both $3 \times 1$ column vectors containing elements from the second and third columns of $H_{t}$. Note that $h_{X, t}$ represents the conditional covariance of changes in exchange rate with returns of the word market portfolio, itself and returns on country index, respectively. Similarly, $h_{M, t}$ represents the conditional covariance of returns of world market portfolio with respectively returns on country index, changes in exchange rate, and itself.

Assuming that the standardized residuals of the proposed trivariate BEKK (1)-GARCH $(1,2)-\mathrm{M}$ model are conditionally normally distributed, then the conditional $\log$-likelihood of residual vector $\mathcal{E}_{t}$ at time $t$ can be written as follows:

$\ell(\theta)_{t}=-\frac{1}{2} \ln (2 \pi)-\frac{1}{2} \ln \left|H_{t}\right|-\frac{1}{2} \varepsilon_{t}^{\prime} H_{t}^{-1} \varepsilon_{t}$ 
The log-likelihood function of the sample becomes $L(\theta)=\sum_{t=1}^{T} \ell(\theta)_{t}$ with $T$ denoting the number of observations. The parameter vector $\theta$ can be estimated by maximizing $L$ with respect to $\theta$. To accommodate the non-normal country stock returns and the exchange rate changes, we estimate the parameters using the quasi-maximum likelihood (QML) estimation method as proposed by Bollerslev and Wooldridge (1992). Under certain regularity conditions, the QML estimates are consistent and asymptotically normal. Hence, statistical inference can be made using the robust standard errors. The required computer programs are coded in GAUSS and the BHHH optimization algorithm is employed to compute the QML estimates.

\section{EMPIRICAL ANALYSIS}

\subsection{Data Description}

Our sample dataset is drawn from five developed markets (the United States, United Kingdom, Canada, Japan, and Australia) and four emerging markets (Korea, Singapore, Taiwan and Thailand). For each country, we use a set of 1824 daily closing prices spanning from 5 January 1999 to 30 December 2005. The series are culled from Morgan Stanley Capital International (MSCI) and DataStream. The country level portfolios are proxied by the MSCI country indexes measured in local currency. The world market portfolio is represented by the MSCI world market index, which is a value-weighted index free from exchange rate fluctuations (see Giannopoulos, 1995; MSCI, 1998). Bilateral exchange rates for the non-US countries are represented by MSCI rates, which are then converted to the dollar price. A trade-weighted exchange rate compiled by the Bank of England is used to measure the exposure of the US assets.

The daily returns (in percentage) of country stock index $(i)$, world market index $(m)$, and the bilateral exchange rate $(x)$ are computed, on a continuously compounding basis, as follows:

$$
r_{j, t}=\ln \left(R_{j, t} / R_{j, t-1}\right) * 100 \quad j=i, m, x
$$

where $R_{j, t}$ and $R_{j, t-1}$ are the closing prices for trading days $t$ and $(t-1)$, respectively.

Table 1 presents the summary statistics for daily returns of country indexes, the world market index and the exchange rate changes. As can be observed in Panel A, all the stock returns exhibit excess kurtosis, ranging from the lowest 1.773 in Japan to the highest 7.06 in Thailand. The Jarque-Bera test statistics for normality is extremely high in all cases, exceeding the $1 \%$ level of significance. It is noted in Panel B that the exchange rate changes are less skewed than the stock returns, and also have smaller kurtosis. The excess kurtosis of exchange rate changes is lower than that of the stock returns in all countries except Taiwan and Thailand. The Jarque-Bera test statistics are all significant at the $1 \%$ level, attesting to non-normal distribution of the exchange rate changes. Such empirical evidence of non-normality in stock returns and changes in exchange rates provides further justification for estimating parameters by the quasi-maximum likelihood method.

The augmented Dicky-Fuller test statistics suggest that the returns of stock indexes, the world market index and exchange rate changes are all stationary at the 5\% level. The Ljung-Box statistics for returns with 20 lags $(\mathrm{Q}(20))$ are statistically significant, indicating that stock returns in Canada, Korea, Taiwan, Thailand, UK and the world market are not free from linear dependencies. Exchange rate changes in the remaining seven countries do not indicate significant linear dependencies, except for Taiwan and Thailand, Moreover, the Ljung-Box test for squared returns at 20 lags $\left(Q^{2}(20)\right)$ are significant at the $5 \%$ level for all the series, thereby indicating some degree of non-linear dependency. Our findings provide some empirical support for employing GARCH-type models to capture the time-varying conditional variance and covariance.

\subsection{Empirical Results}

We report in Table 2 the estimation results of the proposed trivariate BEKK (1)-GARCH $(2,1)$-in-mean model for the nine financial markets using the quasi-maximum likelihood method of estimation. As can be seen from Table 2, all the estimates of the market price of risk, $\lambda_{M}$, show uniformly a positive sign for all countries and are statistically insignificant at the 5\% level, with the magnitudes ranging from the smallest 0.0237 (Canada) to the largest 0.0573 (US). In contrast, the estimates of the currency price of risk $\left(\lambda_{X}\right)$ vary 
remarkably in sign and magnitude across countries ranging from -0.4539 (UK) to 0.0405 (Canada), and are also insignificant at the 5\% level. These findings are consistent with the existing studies, such as De Santis and Gerard (1998) and Cappiello et al. (2003), who find that both the market and currency premiums are insignificant as long as the prices are time-variant. The estimates of GARCH parameters are found to be statistically significant at the 5\% level, thereby suggesting that the conditional variances are highly correlated with the previous ones. We then add an ARCH (2) term (denoted by $d_{j}$ ) in the conditional variance equations of country returns for Singapore, Taiwan and Thailand, and also in the conditional variance equation for the world market returns for all countries (except for Australia, Canada and Japan). It is interesting to note that at least one of the estimated ARCH terms is significant in all the cases except for the world market return for Singapore. Our results suggest the presence of the volatility clustering in country stock markets and in exchange rate markets.

Table 3 reports the summary statistics of the estimated time-varying market betas and currency betas. It is interesting to note that both exhibit a very different pattern in mean value and volatility. The mean values of the currency betas in the developed market economies are much smaller than those in the emerging markets, with the UK even having a negative currency beta. All the four emerging markets show a very high volatility in conditional currency betas in comparison with the developed markets. In addition, the currency betas in seven countries are positively skewed, and all the currency betas are leptokurtic. In a contrast, the market beta in most countries tends to be less volatile than the currency betas, especially in the emerging markets.

\begin{tabular}{|c|c|c|c|c|c|c|c|c|c|}
\hline Coefficient & Ausiralia & Canada & Japan & Korea & Singapore & Taiwan & Thailand & $\mathrm{UK}$ & US \\
\hline$\lambda_{M}$ & $\begin{array}{l}0.0336 \\
(0.76)\end{array}$ & $\begin{array}{l}0.0237 \\
(0.50)\end{array}$ & $\begin{array}{l}0.0346 \\
(0.79)\end{array}$ & $\begin{array}{l}0.0531 \\
(1.16)\end{array}$ & $\begin{array}{l}0,0477 \\
(0.98)\end{array}$ & $\begin{array}{l}0,0486 \\
(1.06)\end{array}$ & $\begin{array}{l}0.0400 \\
(0.80)\end{array}$ & $\begin{array}{l}0.0345 \\
(0.70)\end{array}$ & $\begin{array}{l}0,0573 \\
(1.05)\end{array}$ \\
\hline$\lambda_{x}$ & $\begin{array}{l}-0,0648 \\
(-0,45)\end{array}$ & $\begin{array}{l}0.0405 \\
(0.34)\end{array}$ & $\begin{array}{l}-0,0453 \\
(-0.22)\end{array}$ & $\begin{array}{l}-0,0106 \\
(-0,14)\end{array}$ & $\begin{array}{l}-0,3089 \\
(-0,75)\end{array}$ & $\begin{array}{l}-0,1658^{*} \\
(-1,85)\end{array}$ & $\begin{array}{l}-0,0848 \\
(-1.05)\end{array}$ & $\begin{array}{l}-0.4539^{*} \\
(-1.94)\end{array}$ & $\begin{array}{l}-0,1209 \\
(-0.56)\end{array}$ \\
\hline$b_{i}$ & $\begin{array}{l}0.9800^{* * *} \\
(75.76)\end{array}$ & $\begin{array}{l}0.9765^{* * *} \\
(153.41)\end{array}$ & $\begin{array}{l}0.9606^{* * *} \\
(123.82)\end{array}$ & $\begin{array}{l}0.9848^{* * *} \\
(235.7 \mathbf{1})\end{array}$ & $\begin{array}{l}0.9423^{* * *} \\
(32.68)\end{array}$ & $\begin{array}{l}0.9737^{* * *} \\
(169.72)\end{array}$ & $\begin{array}{l}0.9888^{* * *} \\
(168.24)\end{array}$ & $\begin{array}{l}0.9516^{* * *} \\
(101.41)\end{array}$ & $\begin{array}{l}0.9637^{* * *} \\
(150.79)\end{array}$ \\
\hline$a_{i}$ & $\begin{array}{l}0.1833 \text { * *** } \\
(3.40)\end{array}$ & $\begin{array}{l}0.2083^{* * * *} \\
(7.28)\end{array}$ & $\begin{array}{l}0.2427^{\text {******* }} \\
(8.93)\end{array}$ & $\begin{array}{l}0.1633^{\text {* }} \text { *a* } \\
(6.98)\end{array}$ & $\begin{array}{l}0.2603^{* * *} \\
(2.31)\end{array}$ & $\begin{array}{l}0.1976^{* * * * *} \\
(6.54)\end{array}$ & $\begin{array}{l}0.1323 * * * \\
(4.53)\end{array}$ & $\begin{array}{l}0.2792^{*} \text { *** } \\
(10.82)\end{array}$ & $\begin{array}{l}0.2363 \text { **** } \\
(12.26)\end{array}$ \\
\hline$d_{i}$ & - & - & - & - & $\begin{array}{l}0.1700 \\
(0.66)\end{array}$ & $\begin{array}{l}-0.0912 \\
(-1.31)\end{array}$ & $\begin{array}{l}0.0481 \\
(0,69)\end{array}$ & - & - \\
\hline$b_{x}$ & $\begin{array}{l}0.9877^{* * *} \\
(319.16)\end{array}$ & $\begin{array}{l}0.9922^{\text {*** }} \\
(456.86)\end{array}$ & $\begin{array}{l}0.9728^{* * * *} \\
(101.23)\end{array}$ & $\begin{array}{l}0.9531^{* * *} \\
(93.62)\end{array}$ & $\begin{array}{l}0.9748^{* * * *} \\
(108.60)\end{array}$ & $\begin{array}{l}0.8617^{* * *} \\
(20.88)\end{array}$ & $\begin{array}{l}0.9212^{* * * *} \\
(50.71)\end{array}$ & $\begin{array}{l}0.9837^{\text {**** }} \\
(174.85)\end{array}$ & $\begin{array}{l}0.9855^{\text {t*** }} \\
(184.02)\end{array}$ \\
\hline$a_{\bar{s}}$ & $\begin{array}{l}0.1197 * * * \\
(7.15)\end{array}$ & $\begin{array}{l}0.1175^{* * *} \\
(7.68)\end{array}$ & $\begin{array}{l}0.1351^{\text {**** }} \\
(5.63)\end{array}$ & $\begin{array}{l}0.2664^{* * *} \\
(9.57)\end{array}$ & $\begin{array}{l}0.1465^{* * * *} \\
(4.19)\end{array}$ & $\begin{array}{l}0.5043^{* * *} \\
(4.60)\end{array}$ & $\begin{array}{l}0.3518^{* * *} \\
(8.80)\end{array}$ & $\begin{array}{l}0.1267^{* * *} \\
(6.44)\end{array}$ & $\begin{array}{l}0.1319^{* * * *} \\
(6.10)\end{array}$ \\
\hline$b_{m}$ & $\begin{array}{l}0.9712^{\text {**** }} \\
(72.89)\end{array}$ & $\begin{array}{l}0.9757^{* * *} \\
(122.30)\end{array}$ & $\begin{array}{l}0.9753^{* * * * *} \\
(107.35)\end{array}$ & $\begin{array}{l}0.9617^{* * *} \\
(77.74)\end{array}$ & $\begin{array}{l}0.9652^{\text {***** }} \\
(65.57)\end{array}$ & $\begin{array}{l}0.9620^{\text {*** }} \\
(90.58)\end{array}$ & $\begin{array}{l}0.9644^{* * * *} \\
(83.39)\end{array}$ & $\begin{array}{l}0.9642^{* * * * *} \\
(111.07)\end{array}$ & $\begin{array}{l}0.9610^{\text {**** }} \\
(139.43)\end{array}$ \\
\hline$a_{m}$ & $\begin{array}{l}0.2308^{* * * *} \\
(4.55)\end{array}$ & $\begin{array}{l}0.2111^{* * *} \\
(6.32)\end{array}$ & $\begin{array}{l}0.2119^{* * * *} \\
(5.58)\end{array}$ & $\begin{array}{l}0.1014^{\text {*** }} \\
(3.23)\end{array}$ & $\begin{array}{l}0.1863^{*} \\
(1.84)\end{array}$ & $\begin{array}{l}=0.0039 \\
(0.06)\end{array}$ & $\begin{array}{l}0.1114^{* * * *} \\
(3.11)\end{array}$ & $\begin{array}{l}0.2080^{* * * *} \\
(11.34)\end{array}$ & $\begin{array}{l}0.2410^{\text {*** }} \\
(12,46)\end{array}$ \\
\hline$d_{m}$ & - & - & - & $\begin{array}{l}0.2349 * * * \\
(6.09)\end{array}$ & $\begin{array}{l}-0.1531 \\
(-0.85)\end{array}$ & $\begin{array}{l}-0.2603^{* * * *} \\
(-7.58)\end{array}$ & $\begin{array}{l}-0.2250^{* * *} \\
(-4.79)\end{array}$ & $\begin{array}{l}-0.1149^{* * * *} \\
(-4.21)\end{array}$ & $\begin{array}{l}-0.0447^{* * *} \\
(-4.23)\end{array}$ \\
\hline
\end{tabular}

Notes: $t$-values are in parenthesis, ${ }^{* * * *},{ }^{* *}$ and ${ }^{*}$ indicate significance at the $1 \%, 5 \%$ and $10 \%$ levels, respectively. 
Jayasinghe et al., Modeling Time-Varying Currency Betas

The most notable cases are Taiwan and Korea, with respectively a standard deviation equal to 0.2075 and 0.259 for the market beta in contrast to 1.406 and 1.2186 for the currency beta. It is also noted that the sample kurtosis of currency beta by country is always greater than that of the corresponding market beta. This suggests that the distribution of currency betas tends to have thicker tails than that of the market beta. These features are further demonstrated in Figure 1 where the solid nearly flat line indicates the Hodrick-Prescott filtered trend. As can be seen from Figure 1, the fitted currency betas of Taiwan, Korea and Thailand fluctuate within a wider range than those in Australia, Canada, Japan, and the UK. The estimated time-varying currency beta in the US displays somewhat a meager fluctuation.

We continue to examine whether the timevarying currency betas are mean-reverting and stationary. We employ a widely used seminonparametric test proposed by Gewek and Porter-Hudak (1983) for such a purpose. We first

Table 3: Summary statistics of time-varying currency betas and market betas by country Panel A: Time-varying currency betas

\begin{tabular}{llllllllll}
\hline Coefficient & Aus & Can & Jap & Kor & Sing & Taiw & Thai & UK & US \\
\hline Mean & 0.1049 & 0.0272 & 0.0792 & 0.8661 & 0.1249 & 1.5766 & 0.9098 & -0.1292 & 0.1566 \\
Maximum & 0.7151 & 1.2227 & 0.8646 & 4.8935 & 1.9394 & 7.2367 & 4.1299 & 0.5521 & 0.7431 \\
Minimum & -0.1946 & -0.8770 & -0.7595 & -3.5040 & -2.2617 & -3.0963 & -1.1436 & -1.1903 & -0.2164 \\
SD & 0.1156 & 0.2487 & 0.1952 & 1.2186 & 0.4623 & 1.4060 & 0.6993 & 0.1675 & 0.1157 \\
Skewness & 1.1676 & 1.2890 & 0.0432 & 0.4595 & -0.1745 & 0.2801 & 0.6413 & -0.6004 & 0.7654 \\
Kurtosis & 6.9273 & 11.0618 & 4.6935 & 3.9570 & 6.2937 & 3.9092 & 4.3961 & 7.9853 & 4.9590 \\
J-B stat & 1584.93 & 5438.64 & 218.28 & 133.64 & 832.84 & 86.58 & 272.87 & 1996.26 & 469.25
\end{tabular}

Panel B: Time-varying market betas by country

\begin{tabular}{lccccccccc}
\hline Coefficient & Aus & Can & Jap & Kor & Sing & Taiw & Thai & UK & US \\
\hline Mean & 0.2142 & 0.8664 & 0.5445 & 0.5039 & 0.3573 & 0.3161 & 0.2112 & 0.7851 & 1.2160 \\
Maximum & 0.8762 & 1.8926 & 1.3883 & 1.2852 & 0.9876 & 1.0048 & 0.6305 & 1.4009 & 1.5342 \\
Minimum & -0.0366 & 0.3811 & -0.2390 & -0.3974 & -0.0157 & -0.3414 & -0.0996 & 0.3141 & 0.8252 \\
S D & 0.1264 & 0.2578 & 0.2573 & 0.2590 & 0.1697 & 0.2075 & 0.1365 & 0.1273 & 0.1003 \\
Skewness & 0.9869 & 0.9417 & 0.3113 & 0.4304 & 0.3451 & 0.4033 & 0.6894 & -0.1131 & 0.3863 \\
Kurtosis & 4.8983 & 4.3717 & 2.9397 & 2.4022 & 2.3236 & 3.1833 & 2.5337 & 4.3847 & 3.6682 \\
J-B stat & 563.38 & 412.15 & 29.70 & 83.39 & 70.90 & 51.95 & 160.82 & 149.46 & 79.20
\end{tabular}
perform a one-sided test to check the validity of the null hypothesis that the fractional differencing parameter $(d)$ equals to 0 versus the alternative hypothesis that $d$ is greater than 0 , and then a second one-sided test under the null hypothesis that $d$ is equal to 0 versus the alternative hypothesis that $d$ is less than 1. The GPH test results (not reported but available upon request) show that the null hypothesis is rejected at the 5\% level for all cases at different values of $\alpha$, except for Korea. In the case of Korea, the null hypothesis is only accepted when $\alpha$ is equal to 0 . All the time-varying currency betas series consistently reject both $I(0)$ and $I(1)$ processes. This implies that the betas series may follow a long memory process or an AFIMA process $I(d)$, with $0<d<1$. The GPH test results suggest that the currency betas for Japan, Taiwan and UK are covariance stationary as well as mean-reverting, and the currency betas for Singapore, Thailand and the US are more likely to follow similar patterns, whereas currency betas for Australia, Canada and Korea indicate covariance non-stationary, but mean-reverting dynamics. Our findings indicate that investors may exploit the mean-reverting feature of currency betas for forecasting purposes. This could be very useful in formulating hedging strategies against currency risk.

Figure 1: Time-varying currency betas by country
(a) Australia
(b) Canada
(c) Japan
(d) Korea
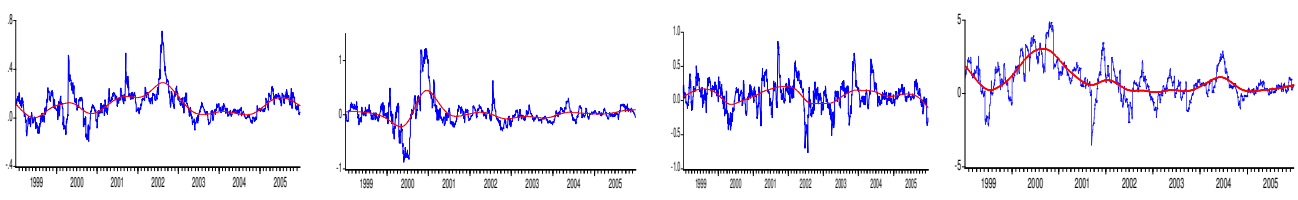

(e) Singapore

(f) Taiwan

(g) Thailand
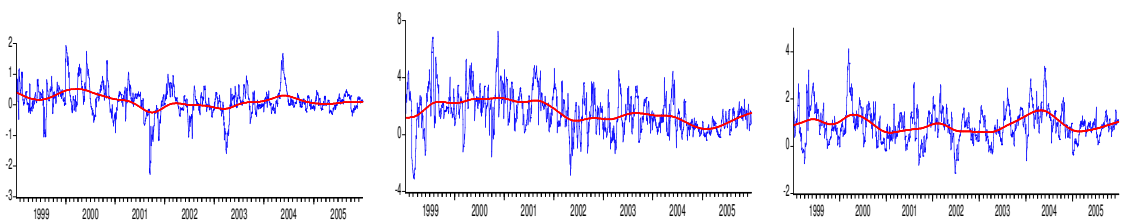
Jayasinghe et al., Modeling Time-Varying Currency Betas

\section{CONCLUDING REMARKS}

In this paper we have employed a trivariate BEKK-GARCH-in mean model to examine the time-varying currency betas and market betas for the selected countries from both the developed and emerging markets using a set of daily data including the returns of country indexes, the world market index and the exchange rate changes spanning from 5 January 1999 to 30 December 2005. The results indicate that the currency betas are generally more volatile than the world market betas, and are also more volatile in the emerging markets like Korea, Taiwan and Thailand than in the developed markets. Based on the results of GPH tests, we find evidence of long-memory of the estimated currency betas and mean-reverting, thereby displaying slow decay. Given that the time-varying currency betas have been computed from the conditional variance and covariance of the return variables, the estimated time-varying currency betas would be more adequate than those estimates without taking the possible correlations into account. Our findings indicate that investors may exploit the mean-reverting feature of currency betas for forecasting purposes. This could be very useful in formulating hedging strategies against currency risk

\section{REFERENCES}

Adler, M. and B. Dumas (1983) "International Portfolio Choice and Corporation Finance: A Synthesis", Journal of Finance, 88(3), 925-984.

Allayannis, G. (1997) “The Time-Variation of the Exchange Rate Exposure: An Industry Analysis”, Working Paper 97-29, University of Virginia.

Allayannis, G. and J. Ihrig (2001) "Exposure and Mark-Ups", Review of Financial Studies, 14(3), 905-935.

Bodnar, G. M. and M. F. H. Wong (2003) "Estimating Exchange Rate Exposures: Issues in Model Structure", Financial Management (Spring), 35-67.

Bodnar, G. M., B. Dumas and R. C. Marston (2002) "Pass-Through and Exposure", Journal of Finance, 107, 199-231.

Bollerslev, T. and J. M. Wooldridge (1992) "Quasi-maximum Likelihood Estimation and Inference in Dynamic Models with Time-Varying Covariances”, Econometric Reviews, 11, 143-179.

Brooks, R. D., R. W. Faff, M. D. Mckenzie and Y. K. Ho (2000) "U.S. Banking Sector Risk in an Era of Regulatory Change: A Bivariate GARCH Approach", Review of Quantitative Finance and Accounting, 14, 17-43.

Brooks, R. D., R. W. Faff and M. Mckenzie (2002), "Time-Varying Country Risk: an Assessment of Alternative Modeling Techniques", The European Journal of Finance, 8, 249-279.

Cappiello, L., O. Castren and J. Jaasakela (2003) "Measuring the Euro Exchange Risk Premium: the Conditional International CAPM Approach”, Working Paper, European Central Bank.

Chiao, C. and K. Hung (2000) "Exchange Rate Exposure of Taiwanese Exporting Firms", Review of Pacific Basin Financial Markets and Policies, 3(2), 201-233.

Choudhry, T. (2001) "The Long Memory of Time-Varying Beta: Examination of Three Emerging Asian Stock Markets”, Managerial Finance, 27(1/2), 5-14.

Choudhry, T. (2002) "The Stochastic Structure of the Time-Varying Beta: Evidence from UK Companies", The Manchester School, 70(6), 768-791.

Choudhry, T. (2005) "Time-Varying Beta and the Asian Financial Crisis: Evidence from Malaysian and Taiwanese Firms", Pacific-Basin Finance Journal, 13, 93-118.

De Santis, G. and B. Gerard (1998) "How Big is the Premium for Currency Risk?" Journal of Financial Economics, 49, 375-412.

Dominguez, K. M. E. and L. L. Tesar (2006) "Exchange Rate Exposure", Journal of International Economics, 68, $188-218$.

Gewek, J. and S. Porter-Hudak (1983) "The Estimation and Application of Long Memory Time Series Models", Journal of Financial and Quantitative Analysis, 13, 101-116.

Giannopoulos, K (1995) "Estimating the Time Varying Components of International Stock Markets' Risk", European Journal of Finance, 1, 129-164.

Gonzales-Rivera, G. (1996) "Time-Varying Risk: The Case of the American Computer Industry", Journal of Empirical Finance, 2, 333-342.

Hunter, D. M. (2005) “Time-Varying Exchange Rate Exposure of Small and Large Firms”, Working Paper, University of South Florida.

Lim, G. C. (2005) “Currency Risk in Excess Equity Returns: a Multi Time-Varying Beta Approach”, Journal of International Financial Markets, Institutions and Money, 15, 189-207.

MSCI, (1998) Methodology and Index Policy, Morgan Stanley Capital International.

Williamson, R. (2001) "Exchange Rate Exposure and Competition: Evidence from the Automotive Industry", Journal of Financial Economics, 59, 441-475. 